\title{
A ceia do Senhor e o tema do Sacrifício
}

\author{
The Lord's Supper \\ and the theme of sacrifice
}

Manoel Pacheco de Freitas*

Resumo: 0 método critico literário aproximará a pesquisa ao significado que Jesus deu a forma de sua morte. A revelação plena dessa consciência é explicita na ultima ceia. As etapas de seu ministério radicado no âmago das questões sobre o direito à vida, testemunhado pela ambientação social, na qual se inseriu e no profundo encontro com a pessoa que morre - pelo pecado ou pela enfermidade - reúnem a descrição clara de sua interpretação sobre a sua morte: redentora

Palavras-chave: Ceia; Sacrifício; Morte; Revelação.

Abstract: The critical literary method will approach the search to the meaning that Jesus gave the form of his death. The full revelation of this consciousness is explicit at the Last Supper. The stages of his ministry rooted in the heart of the questions about the right to life, witnessed by the social environment in which he was inserted, and the profound encounter with the person who dies - by sin or illness - have a clear description of his interpretation of his death: redeeming.

Keywords: Supper; Sacrifice; Death; Revelation.

* Doutor em Teologia, professor da FAJOPA, Faculdade João Paulo II, Marília, SP. 


\section{Introdução}

A reflexão ousa, embora o método aplicado, seja contemplativa, ver no quadro da ultima ceia refletida a experiência de uma crucifixão que está sendo já vivida interiormente. Este real estado interior de Jesus, que será visível a todos mais tarde é a sua paixão que dará sentido sacrifical e salvífico de sua morte definido por Ele. A morte torna-se o testamento de sua Palavra, vinda do Pai e verdadeira. Sua morte o revela e revela o Pai. O sacrifico revela a sua pertença ao Pai e o que é o Pai pertence a Ele. Com sua morte Ele abraça definitivamente a sua comunhão com o Pai, indo ao encontro de sua paixão e morte, livremente, Ele não cai em contradição com a sua Palavra, isto é, “a salvação”. Ele é a testemunha da salvação através de sua morte fiel.

\section{1. "Jesus vai ao encontro de sua paixão e morte"}

Os Evangelhos Sinóticos - em sua atual redação - permitem perceber os extremos de um período bem circunscrito da vida e da obra de Jesus: aquele que vai da morte do Batista, por iniciativa de Herodes Antipa, e que termina com a chegada de Jesus a Jerusalém, para o último período de sua existência terrena. Vendo:

A morte do Batista: Mc 6, 14-2 = 9,7-9; Mc 14, 1-12 = Lc 9, 7-9. A chegada a Jerusalém: Mc. 11, 1 = Mt 21, 1 = Lc 19, 28 (= João 1, 12).

Para se determinar melhor o período, podem ser levantados mais alguns dados evangélicos:

A obra de anúncio do Reino de Deus na Galileia era substancialmente falida. É significativa, nesse sentido, a lembrança do episódio na sinagoga de Nazaré, justamente nessa circunstância: Mc 6, 1-6; Mt 13, 53-38;

Herodes Antipa interessa-se por Jesus, cuja fama já se tinha espalhado, concluindo: João Batista ressuscitou: cf. Lc 9, 7-9.

Jesus leva consigo os discípulos e se afasta definitivamente da Galileia: anekhoresen (Mc 6,32); apelthon (Mt 14,13); hupekhóbesen (Lc 9,10). 
Distribuindo a temática referente à eucaristia, presente nessa seção evangélica, podemos nos deter sobre os seguintes temas: características e temáticas dos textos; premissas galiléicas; o "logion" de Jesus sobre a sua morte; os anúncios da paixão-ressurreição; compreensão-reação dos discípulos.

\section{A) Características e temáticas dos textos}

Em primeiro lugar, um olhar geral nos textos evangélicos: eles levam a marca evidente de sua história dentro da pregação e da experiência eclesial primitiva. Com efeito, apresentam-se com os elementos de estruturação comum das partes como se vê na ordem de sucessão dos anúncios da paixão, e manifestam desenvolvimentos próprios de cada redator evangélico. Limitamo-nos a fornecer a indicação dos três pontos seguintes: Jesus em diáspora segundo os Sinóticos; temática geral dos textos e nota bibliográfica.

\section{Jesus em diáspora segundo os Sinóticos}

As seções evangélicas, situadas entre os dois episódios extremos da morte do Batista e da chegada de Jesus a Jerusalém, são: Mc 6,3010, 52; Mt 14,13-20; Lc 9,10-19,27.

Além das inserções temáticas próprias de cada evangelista, podemos apontar as seguintes ocorrências:

Jesus está fora da Galileia e longe de sua cidade (Cafarnaum). Em comparação com o período anterior, a mobilidade de sua vida é muito maior: na Fenícia; nas redondezas de Cesareia de Filipe; no território da Decápolis.

Nesse período são frequentes seus encontros com não hebreus (os “distantes”), dos quais é ressaltada a fé;

No estado atual dos textos, são frequentes alguns temas "sinóticos": a formação de fé dos discípulos; a lembrança das antigas experiências do povo de Deus, como o maná (multiplicação dos pães), 
a passagem do Mar Vermelho (Jesus caminha sobre as águas), a lei sinaítica (discussões com os escribas);

São também evidentes o trabalho redacional e a mensagem de cada evangelista: a "seção dos pães” em Mc 6,31-8, 26; a "viagem em direção a Jerusalém” em Lc 9,51-29,27; a elaboração do “projeto Igreja” em Mt 14-16.

Para o estudo dessas páginas "redacionais” pode-se ver, além do já citado artigo de L. Cerfaus sobre a “divisão dos pães”, também outros. ${ }^{1}$

Pois bem, pertence a esse período (de diáspora) da existência terrena de Jesus um tema recorrente: o anúncio por parte de Jesus de sua paixão e morte. Qual o seu sentido? Como isso se relaciona com a experiência de Jesus e com sua obra de fundação da nova comunidade dos discípulos? Há alguma relação com a instituição da Eucaristia?

\section{Temática geral dos textos}

Estamos, portanto, diante do tema da cruz, assim como foi vivenciado e apresentado por Jesus. Do ponto de vista exegético-teológico, o tema é atual. Segundo estudos recentes, estaríamos diante de um dos capítulos de "cristologia implícita". ${ }^{2}$ Mais precisamente: por meio de diferentes redações evangélicas é possível conhecer a consciência que Jesus tinha de si e de sua missão de "Servo" e salvador dos homens.

São já numerosos os estudos dedicados recentemente ao tema de Jesus diante de sua morte. Indicamos alguns títulos:

\section{B) Premissas galileicas}

A pergunta à qual se pretende responder neste capítulo é a seguinte: com que consciência e com que entendimento Jesus se afasta

W.GRUNDMANN, Fragen der Komposition des lukanischen Reiseberichtes, Zeitschritf für neu-testamentliche Wissenschaft, 50 (1959) 252-270;

2 W.C. ROBINSON, The Theological Content for Interpreting Luke's Travel Narrative, JBS 79 (1960) 20-31; X. LEON-DUFOUR, Verso l'annuncio della Chiesa (Studio di struttura di Mt 14,1-16,20), in “Studi sul Vangelo” Paoline, Milano 1967, pp. 315-350. 
da Galileia para iniciar a assim chamada grande viagem? Podemos responder examinando, sobretudo, a série de antigas "parábolas do reino" que falam de formas variadas do mistério da vida que se encontra na "semente" e de suas leis estranhas, e o logion sobre o esposo que será “tirado violentamente”: passagens que se referem ao período galiléico, segundo a opinião difundida entre os exegetas.

\section{As parábolas do Reino}

Vamos considerar as primeiras parábolas centradas no reino. Elas se encontram em:

Mc 4,1-34: encontramos um "discurso parabólico" inicial, no qual, além da temática do "por que falar mediante parábolas" $(4,10$ 12. 33-34) e da menção à lâmpada que não deve ser colocada debaixo de uma vasilha $(4,21-25)$, encontramos a insistência na semente e no seu mistério: parábola do semeador, com a explicação (4,3-9. 13-20); parábola da semente que brota sozinha (4,26-29); parábola do grão de mostarda $(4,30-32){ }^{3}$

Mt 13,3-52: o discurso parabólico torna-se mais articulado. Ele se inicia com a sucessão "parábola do semeador - pergunta por que Jesus fala mediante parábolas - explicação da parábola do semeador” $(13,2-23)$ e continua com as parábolas do joio, do grão de mostarda e do fermento. Há uma retomada temática sobre a razão pela qual Jesus fala mediante parábolas (13,34-35), seguida pela explicação da parábola do joio (13,36-43). As parábolas do tesouro e da pérola e aquela da rede $(13,44-50)$ preparam a conclusão;

Lc 8,4-15: relata somente a sequência originária: "parábola do semeador - pergunta sobre a razão pela qual Jesus fala mediante parábolas - explicação da parábola do semeador”.

A. GEORGE, Comment Jésus a-t-il perçu sa proper mort, "Lumière et Vie”, 20 (1971) 34-59; J. GUILLET, Gesù di fronte alla sua vita e alla sua morte, Cittadella, Assisi 1972. 
A parábola do semeador e a respectiva explicação podem nos indicar como possa ter surgido em Jesus a consciência do valor a ser dado aos insucessos e do sentido que deve ser atribuído a uma eventual morte.

a) Distinguimos a "parábola" em si da "explicação" que é colocada na boca de Jesus. Essa última, por motivos de linguagem, é atribuída pelos exegetas à compreensão da igreja pós-pascal. Todavia, a igreja não trabalhou no vazio: muito provavelmente elaborou uma explicação primitiva de Jesus que falava não da "palavra semeada", mas do "reino semeado".

b) A explicação feita "na casa" dos seus: é constante a tradição segundo a qual Jesus explicava aos seus muitos ensinamentos. Metodologicamente é importante estabelecer o público ao qual Jesus se dirige. Podemos, portanto, imaginar uma explicação da parábola feita para seus discípulos. E isso não em termos "livres", mas em termos literariamente bem configurados. Podemos adotar como esquema a explicação atual da palavra centrada no conceito de "palavra semeada". Considerando o sentido e o valor dos verbos, podemos supor que o conceito central seja aquele de “reino semeado”. Havia certa alegorização da parábola, talvez inevitável, mas permanece fundamental a construção parabólica da narrativa, a qual, por sua vez, apoia-se não na sucessão, mas no contraste entre os resultados dos primeiros três terrenos e o tríplice florescimento extraordinário do quarto terreno. Nesse contraste está apontado o "drama” do reino semeado e não a responsabilidade da recepção por parte dos terrenos interessados. E também para o "reino semeado" vale a mesma lei que Jesus tinha indicado para sua obra e sua pessoa: são inevitáveis (ou necessários) os primeiros insucessos para se chegar ao florescimento prodigioso previsto pelo semeador divino.

c) O aprofundamento da igreja pós-pascal: também a explicação atual traz o mesmo ensinamento. Dessa vez, ele explica o drama 
da "palavra semeada”. Aqui também não devemos parar no drama psicológico de cada terreno que "recebe", compreende" etc., ainda que, sobretudo na redação de Lucas e Matheus, haja certa insistência nas reações "humanas" dos terrenos, certa concessão ao processo de alegorização. Aqui também devemos, acima de tudo, perceber o grande "drama da Palavra” para a qual é previsto o maravilhoso florescimento final, com as mesmas leis indicadas para a "pessoa de Jesus” e para o "reino semeado”. Há uma intencionalidade significativa em transferir para a "palavra" a grandiosidade dos aspectos e das leis do "reino" e a "personalidade" da experiência de Cristo: mas os textos dos Atos, assim como o uso do termo "palavra" no Evangelho de Marcos justificam amplamente essa visão. ${ }^{4}$

\section{A) 0 logion sobre o esposo que "será raptado (subtraído violentamente)"}

A consciência que Jesus tinha ao deixar a Galileia pode ser intuída também no logion do “esposo que será subtraído violentamente”. Ele se encontra em: Mc 8,18-20; Mt 9,14-15; Lc 5,33-35, no contexto mais amplo do banquete oferecido pelo publicano convertido e chamado por Jesus a fazer parte dos seus apóstolos: Levi-Matheus.

a) As redações: as atuais redações são muito personalizadas, mesmo aquela mais próxima do original;

- Lucas é aquele mais contextualizado: tudo é regido "Por que vocês comem e bebem com os pecadores?”; “Comer e beber com...” está muito mais ligado à conversão e à vida nova; por isso destaca-se a nova piedade trazida por Cristo e centrada na "alegria”; por isso a insistência sobre o radicalismo da novidade trazida por Cristo;

AA.VV., La sapienza della croce, Vol. I, Elle Di Ci, Torino 1976 (especialmente, os artigos de: C. Duquoc, pp. 11-14; A.P. Gordo, pp. 106-125; J. L. CHORDAT, Jésus devant as mort dans l'Evangile de Marc, Du Cerf, Paris 1972. 
- Matheus: é menos contextualizado. É significativo o contraste entre o "nós" dos discípulos de João e o não jejum dos discípulos de Jesus; vislumbra-se a igreja de Matheus nessa pergunta sobre a relação com os discípulos de João e o atraso da parusia;

- Marcos: há um acréscimo: “Irão jejuar naquele dia”. O contexto é eclesial e a observação é em função do sentido a ser dado ao jejum da sexta-feira, que começava a ser uma prática cristã. E o sentido que aflora é dúplice: Cristo ainda não veio completamente e o cristão participa do mistério pessoal de Cristo.

b) A fonte comum: é reconstituível facilmente:

Os discípulos de João chegam e lhe [a Jesus] dizem:

"Por que os discípulos de João jejuam,

e os seus discípulos, ao contrário, não jejuam?”

Jesus lhes respondeu:

“Não podem jejuar os 'filhos das núpcias' [=os convidados de um casamento]

enquanto o noivo está com eles;

durante todo o tempo em que o noivo estiver com eles não podem jejuar.

Chegarão, porém, dias em que o noivo será arrancado deles; então, jejuarão"

O sentido do logion principal pode ser estabelecido por esses fatos: ${ }^{5}$

- os protagonistas são os discípulos de João;

A pesquisa é imponente, apresentamos os resultados de maior expansão no consenso dos estudiosos: M. BASTIN, Jésu devant as mort, (Lectio Divina, 92), Du Cerf, Paris 1976; H. SCHURMANN, Comment Jésus a-t-il vécu as mort? Exégèse et théologie, (Lectio Divina, 93), Du Cerf, Paris 1977; P. GARDEL, La Cène et la croix. Après Renès Girard; réflexion sur la mort rédemptrice. "Nouvelle Revue Théologique”, 101 (676698); X. LEON-DUFOUR, Face à la mort, Jésus et Paul, (Parole de Dieu, 18), Du Seuil, Paris 1979; M. GOUGUES (a cura), Jésus devant sa passion et sa mort, (Cahiers Evangile, 30), Du Cerf, Paris 1979. 
- a resposta de Jesus está articulada em dois logia: um indireto e genérico de tipo sapiencial: "não podem jejuar...”; e um em estilo direto sobre "chegarão dias";

- a intenção é responder à pergunta sobre o sentido do jejum que está surgindo como prática cristã na sexta-feira (cr. Atos 13,21);

- o sentido do jejum cristão é diferente daquele dos judeus, representados pelos discípulos de João: para eles era um jejum de espera e podia ter o sentido de purificação e de preparação para a guerra dos filhos da luz contra os filhos das trevas (Qumran); para os cristãos, ao contrário, ele se refere ao "noivo que é subtraído de forma violenta” e é feito na esperança cristã típica "até que ele chegue”.

É um fato histórico que é contado ou estamos diante de um gênero literário diferente do gênero histórico? Literariamente, o trecho é um apoftegma, isto é, uma narração histórica resgatada para emoldurar um dito sapiencial ou profético; consiste em dois ditos do Senhor emoldurados por um fato, o que privilegia o sentido das afirmações e sua mensagem, mais do que a consistência histórica da narrativa; e o conteúdo querigmático pode ser expresso: "chegou o tempo das núpcias, porque o noivo está presente”; mas “o noivo será tirado temporariamente dos filhos das núpcias de maneira violenta”.

c) As "ipsissima verba" de Jesus: não é impossível recuperar o Cristo pré-pascal. Basta levar em conta esses fatos:

- o contexto da polêmica entre Jesus e João, entre os discípulos de Jesus e aqueles de João; o conhecido "processo de historicização" típico, sobretudo, de Mateus que nos leva de volta, imediatamente, para a igreja primitiva, mas dessa forma nos conduz facilmente a situações análogas diretamente relacionadas a Cristo; as perguntas que são dirigidas a Jesus nessa polêmica com João não são ingênuas e revelam preocupações de fundo 
(cf. Mt 1,12-15 e Lc 7,18-28; Jo 3,25-36); e as repostas de Jesus remetem para aquilo que ele está fazendo;

- tudo isso data, provavelmente, da época em que Jesus ainda estava vivo e podia-se pedir a ele que jejuasse no sentido da espera típica dos discípulos de João.

Tudo isso demonstra que Jesus tem uma consciência dúplice e surpreendente em relação ao tempo de sua presença física e ao tempo posterior à sua morte; o seu tempo é o tempo das núpcias e não da espera; mas o tempo da igreja é caracterizado por uma presença-ausência do noivo devida à maneira come ele "seria tirado (Grego) dos filhos das núpcias".

\section{B) 0 "logion" de Jesus sobre sua morte}

Todavia, a consciência da possibilidade de um fim violento e sua intenção de não se deixar esmagar pelo aspecto negativo podem ser percebidas mais claramente na seção que relata a progressiva aproximação de Jerusalém. Na atual estrutura redacional dos Evangelhos Sinóticos encontramos anúncios repetidos de Jesus sobre sua morte violenta e sobre o sentido que ela assumia para o seu olhar e sua consciência. Esses anúncios são numerosos especialmente na seção evangélica referente à diáspora de Jesus: o tempo que vai da decapitação do Batista à chegada de Jesus a Jerusalém.

Não é difícil distinguir - nessas páginas que evocam as previsões de Jesus sobre a sua paixão - a formulação apostólica ("redacional”) do tema da "ipsissima vox" originária de Jesus. É a essa última voz que pretendemos chegar aqui. ${ }^{6}$

Distinguimos, brevemente, dois momentos: a concepção de uma morte "vicária” na época de Jesus; o logion de Mc 10,4b = Mt 20,28 sobre o sentido do "servir"; o logion sobre o "pegar a própria cruz".

6 Cf. M. Bastin, op. cit., p. 83-100. 
I. A concepção de uma "morte vicária” na época de Jesus

a) A literatura rabínica: hoje estamos em condição de conhecer o pensamento palestino da época de Jesus. Em relação ao nosso assunto: esperava-se um Messias sofredor e redentor, na linha de Is 53, mas não se tem certeza de que houvesse claramente uma concepção de uma "morte vicária". ${ }^{7}$ Somente poucos textos, geralmente datados de 200 d. C., com uma possível influência cristã, nos fornecem alguns elementos sobre: ${ }^{8}$

- a dor como elemento de expiação;

- o valor expiatório da morte para os próprios pecados;

- o valor vicário da morte de um justo;

- o valor expiatório das nações pagãs para Israel;

- o valor expiatório para Israel dos padres e dos profetas.

b) O patrimônio inspirado: mas se os testemunhos da literatura rabínica são incertos e discutíveis, Jesus podia encontrar nas escrituras do Antigo Testamento uma linha de pensamento não tão nebulosa como costumamos imaginar. Podemos apontá-la nos seguintes pontos nodais:

- uma tradição longa e articulada sobre os sofrimentos e as perseguições que os profetas encontraram em sua pregação e em sua experiência profética, como por exemplo, Oseias e Amos;

- o caso de Jeremias "profeta a custo da vida”, o "profeta da crise": não se satisfaz em ser a "boca de Deus" para o seu povo ou simples porta-voz de Deus, mas ele vive em sua experiência o juízo que está anunciando ao seu povo por ordem de Deus (cf. o celibato como sinal profético do fim do país (Jr 16,1-13), a “paixão” de Jeremias como parte do livro profético de Jeremias (Jr 36-45); as “confissões de Jeremias” como expressão de um

\footnotetext{
7 Cf. M. Bastin, p. 90-100.

8 M. BASTIN, op. Cit., pp. 83-100.
} 
profeta totalmente do lado de Deus e do povo (Jr 11,18-21; 12,16 ; 15,10-21; 17, 14-18; 18,18-23; 20,7-11.12-13; 20,14-18);

- Ezequiel “sentinela” responsável de quem Deus cobra seu poder de vida ou morte; ${ }^{9}$

- longa tradição sobre Moisés profeta e intercessor; ${ }^{10}$

- a figura do "Servo sofredor para os outros” de Is. 52,13-53,12. É um trecho que retoma a função de intercessão típica dos profetas a partir de Jeremias e demonstra como o envolvimento da pessoa do profeta na mensagem é um processo rico de desdobramentos teológicos. Além disso, acrescenta elementos significativos de novidade: a profundidade e a medida desse sofrimento, a voluntariedade desse sofrimento, um sofrimento que desemboca na glorificação, o reconhecimento do valor salvífico por parte das nações, valor não estritamente nacionalista, mas universal dessa experiência.

c) Jesus diante da morte dos outros: para se compreender mais o pensamento de Jesus sobre a sua morte poderia ajudar a observação evangélica sobre Jesus nos momentos em que se coloca diante da morte dos outros. ${ }^{11}$

II. O logion sobre as possíveis dimensões do "servir"

Mc 10,45

“... entre vocês não é assim ...

porque também o Filho do homem

não veio para ser servido

mas para servir e dar a sua vida (como) resgate para muitos”.
Mt 20,28

“... entre vocês não seja assim ... como o Filho do homem, que não veio para ser servido mas para servir e dar a sua vida (como) resgate para muitos”.

9 Cf. Ez 3, 16-21; 33, 1-9; 13,5.

10 Cf. Salmo 106,23; Es 32,7ss; Dt 9,19; 3,4; 18,18.

11 X. LEON-DUFOUR, Face à la mort. Jésu et Paul, ("Parole de Dieu”), 18, Du Seuil, Paris 1979, pp. 29-71. 
Os estudiosos percebem em Mc 10,45 = Mt 20,28 uma vox Jesu ipsissima e muito importante para compreender a consciência que Jesus tem de si. Provavelmente, o texto atual de Mc 10,35-45 e par. seja composto por três trechos distintos originariamente:

a) aquele referente a uma disputa entre discípulos a respeito de quem é o maior do Reino: Mc 10,41-44 = Mt 20,24-27 = Lc $22,24-27 ;^{12}$

b) a pergunta-ambição dos filhos de Zebedeu: Mc 10,35-40 = Mt $20,20-23$;

c) o logion acrescentado de: Mc 10,45 = Mt 20,28.

Como observam Jeremias e Bastin (l.c.), esse último logion pré-pascal foi acrescentado por Mt-Mc: sua versão inteligível helenizada está em 1 Tim 2,6. Com efeito, nos nossos dois textos a fórmula é totalmente "semítica" e diretamente dependente de Is 53,10-11 (somente seria corrigido e substituído o eu de Jesus com a expressão "filho do homem”). Essa declaração de Jesus poderia ter sua origem na indicação-palavra do Pai no Batismo e durante a transfiguração: Mc 1,11 e 9,7 (e par.), justamente indicados em relação a Is 42,1.

III. O logion sobre "pegar a cruz"

Mc 8,34

E, chamada a si a multidão

com seus discípulos

disse-lhes:

"Se alguém

quiser seguir após de mim, renegue a si mesmo

e pegue a sua cruz

e siga-me”.
Mt 16,24

Lc 9,23

Jesus disse aos seus discípulos:

"Se alguém

quiser vir após mim renegue a si mesmo e siga-me".
Se alguém quiser vir após mim renegue a si mesmo e siga-me”.

12 Cf. Jo 13,4-20; Mc 9,35-50; Mt 18,1-9. 


\section{Mt 10,37-38}

"Quem está ligado ao pai e ou à mãe mais do que a mim não é digno de mim; e quem estiver ligado ao filho ou à filha mais do que a mim, não é digno de mim;

e quem não pega a sua cruz e não segue atrás de mim, não é digno de mim”.
Lc 15,26-27

"Se alguém vier até mim e não odeia seu pai e sua mãe e a mulher e os filhos e os irmãos e as irmãs e ainda a sua própria vida, não pode ser meu discípulo.

Aquele que não leva a sua cruz e não vem atrás de mim, não poderá ser meu discípulo"

Encontra-se numa série dúplice: uma ambientada no convite à sequela (Mc 8,34; Mt 16,24; Lc 9,23), outra relacionada às exigências dessa sequela (Mt 10,38; Lc 14,27), em contextos históricos também diferentes. Pode o Cristo pré-pascal ter falado de cruz, quando a forma normal de morte para um judeu era eventualmente a da lapidação?

a) Redacionalmente: nas possíveis redações do logion de Jesus, destaco R. Bultmann ${ }^{13}$ e a seguinte evolução:

- na boca de nosso Senhor, quando inicia sua viagem e compreende que a morte pode ser uma saída possível de sua missão, o logion pode ter o sentido de um alerta: se quiserem ainda seguir-me, devem estar preparados também para a morte (por lapidação ou outro suplício).

- na fonte Q (onde estão reunidos os logia primitivos de Jesus) a frase adquire um sentido negativo:

- na formulação de Mc o pegar a cruz é algo positivo para perceber a maneira de tornar-se discípulos de Cristo e viver o mistério pascal;

- a redação de Lc evidencia que se trata de "pegar a cruz" de maneira não literal, porque se trata de sofrimentos da vida cotidiana.

13 R. BULTMANN, Theologie des Neuven Testaments, Tubingen, 9. ed. 1984. J. JEREMIAS, Teologia del Nuovo Testamento, Paideia, 1976. 
b) Historicamente: pode Jesus ter expressado esses conceitos com a imagem da cruz? Há diversas explicações:

- poderia ser um ditado popular: a cruz indicava o suplício ao qual, naquele tempo, eram condenados muitos zelotes: portanto, a possibilidade de morrer na cruz não era remota;

- Cristo, na sua consciência não comum, podia perfeitamente prever desde o início o êxito real de sua missão, e propõe-se, então, aos seus discípulos como modelo, inclusive nas exigências mais radicais;

- o ditado pode ser interpretado como construído inicialmente sobre o termo "jugo" e, posteriormente, segundo o entendimento da Igreja, pode ser interpretado com a imagem da cruz;

- analogamente pode ser compreendido, partindo, porém, do conceito de "tau”, que significa pertença;

- outra tentativa reforça o sentido de cruz, como suplício de escravos e, apelando para a maneira paradoxal que Cristo às vezes utiliza, indica na imagem o convite a se tornarem seus escravos para participarem de sua glória.

\section{C) Os anúncios da paixão ressurreição}

Outra indicação para se entender a consciência de Jesus sobre sua paixão é constituída por vários anúncios de sua morte feita por ele. Os Evangelhos oferecem diversos testemunhos disso.

Para aprofundar esse item vejam-se os estudos já indicados: ${ }^{14}$

I. Os testemunhos evangélicos

Quantas vezes Jesus falou de sua paixão e morte, isto é, do tipo de conclusão de sua existência, entendendo uma morte violenta por parte dos homens, com valor redentor para todos (na linha de Is 53)?

J. JEREMIAS, op. cit., pp. 315-326: A.P. GORDO, Gli annunci dela passione, in "La sapienza dela croce”, Vol. I, Elle Di Ci, Torino 1976, pp. 106-125; X. LEON-DUFOUR, op. cit., pp. 73-100; H. SCHÜRMANN, op. cit., pp. 76-69; M. BASTIN, op. cit., pp. 123-167. 
É praticamente impossível responder a essa pergunta. No estado atual dos testemunhos evangélicos, podemos organizar os dados seguintes:

a) durante o período galiléico, Jesus teria aludido à sua morte trágica na fala já analisada sobre o noivo subtraído drasticamente da alegria dos amigos, de maneira a trazer para eles tempos de luto e jejum (cf. Mt 9,15; Mc 2,19-20; Lc 5,34-35) e nas parábolas do reino ${ }^{15}$ (especialmente naquela do semeador).

b) no tempo da "diáspora" de Jesus (aquele que estamos examinando), os anúncios da paixão-ressurreição constituem um tema dominante. Podemos indicar dois tipos de texto:

- os três anúncios clássicos, que marcam toda a parte referente à “diáspora” de Jesus:

Mt 16,21 = Mc 8,31= Lc 9,22

$17,22-23=9,31=9,44$

- outras menções de Jesus a respeito de sua paixão e morte:

Mt 17,12 = Mc 9,12 = após a transfiguração

Lc 12,49-50 = o "batismo"

Lc 13,32-33 = o "profeta” assassinado

Mt 20,23 = Mc 10,39 = "cálice" e "batismo"

Mt 20,28 = Mc 10,45 = o logion já visto

c) em Jerusalém, durante a última permanência de Jesus na cidade santa (de que falaremos mais adiante), os Sinóticos evocam outras alusões mais ou menos explícitas sobre a morte de Jesus:

- dirigindo-se aos escribas e aos chefes, o Mestre fala de si na parábola dos vinhateiros homicidas: Mt 21,33-36; Mc 12,1-12; Lc 20,9-19;

- aos seus discípulos Jesus procura oferecer repetidamente o sentido das parábolas:

15 Sobre esses temas fundamentais seguimos as pistas abertas por: X. L EON-DUFOUR, op. cit., p. 73, 97-98; H. SCHÜRMANN, pp. 21-81; J. JEREMIAS, op. cit., p. 327. 
Mt 26,12 $=$ Mc 14,8 $=$ Jo 12,7 $=$ ceia em Betânia

Mt 26,31-31 $=$ Mc 14,27-28 = pastor espancado (Zac 13, 7)

Lc 22,37 = com os ímpios (Is 53,12)

II. Os temas fundamentais

Nessas páginas referentes ao sentido da paixão de Jesus - por além do nível redacional próprio de cada evangelista e também da sistematização da pregação apostólica - é possível perceber a consciência e o anúncio de Jesus sobre o sentido de sua morte. Indo em direção a Jerusalém, ele enxergou e revelou com uma clareza cada vez maior a ligação entre sua missão no meio dos homens e a conclusão trágica de sua existência.

Alguns dados:

a) Jesus previu e anunciou sua morte violenta à luz de um dúplice elemento fundamental:

- a consciência de seu papel profético, no meio do povo que desde sempre tinha recusado os profetas (cf. o fim recente do profeta Batista: Mt 11,7-15 e 17,10-13; 23,29-39 e par.; e o logion sobre o profeta recusado na sua pátria: Mt 13,57 = Mc 6,4- Lc 4,24= Jo 4, 44);

- a vontade de Jesus de permanecer fiel ao projeto de seu Pai, remetendo para um modelo dúplice de fidelidade ao Antigo Testamento, aquele do "servo" e aquele do "justo" ao qual cabe o destino de humilhação-exaltação (como em Is 53; em Daniel; na figura de José em Gn 37,50 etc.);

b) Jesus atribuiu um sentido profundo a essa previsão sobre 0 fim de sua vida. Qual? Poderíamos resumir três soluções correntes:

- Jesus não somente previu, mas procurou a sua morte em função da afirmação do Reino de Deus;

- Jesus aceitou a morte quase por necessidade inevitável, ou até mesmo por surpresa; 
- Deus Pai “entregou" seu filho à morte e Jesus foi voluntariamente ao encontro dela, assumindo sobre si os pecados dos homens para reconciliá-los assim com Deus.

No tocante à posição de Dufour, ${ }^{16}$ achamos legítimo deduzir dos textos que: não somente Jesus foi ao encontro da morte voluntariamente, por ela ser a conclusão inevitável de sua missão profética e de sua fidelidade a Deus Pai, mas ele também "compreendeu e expressou o sentido 'sacrifical' de sua morte violenta, seja à luz de sua citação indiscutível a Is 53, seja à luz da última ceia celebrada por Jesus”.

c) Para responder a essa mesma pergunta, podemos retomar a obra de H. Schürmann. ${ }^{17}$ Ele responde a um conjunto de perguntas colocadas no intuito de entrar na psicologia de Jesus de Nazaré, em sua consciência "humana”.

1. Jesus não podia prever seriamente a possibilidade de um seu fim violento? Responde positivamente, pois Jesus tinha diante dos olhos a maneira concreta de agir dos poderes civis, representados por Herodes e pelos Romanos, e das autoridades religiosas, representadas pelos partidos dos fariseus e dos saduceus.

2. Podemos estabelecer com verossimilhança que Jesus estava preparado para a eventualidade de uma morte violenta? Com base em textos como Mc 14,32-42 e paralelos, Mc 8,34 e paralelos (predições da paixão), Lc 12,22b-24 e 50 (“não se preocupar pela vida” e o "batismo" desejado), o autor responde afirmativamente.

3. O conhecimento do perigo de morte condicionou o comportamento de Jesus? Ele apresenta como reações de Jesus a esse conhecimento os seguintes gestos: manda os discípulos em missão (Lc 10,1 e paralelos), entra em Jerusalém e tenta provocar uma decisão definitiva (Mc 11,1-10), "purifica” o templo (Mc 11,15-16 e paralelos), institui a eucaristia.

\footnotetext{
16 X. LEON-DUFOUR, op. cit., p. 97.

17 H. SCHURMANN, op. cit., p. 21.
} 
4. Jesus pôde conciliar sua morte com sua missão? O gesto de renúncia que ele realiza antes da última ceia (Lc 22,15-8; cf. Mc 14,15), demonstra como ele sabia dar um sentido profundo a uma renúncia que chega à morte; assim como demonstra ter consciência de que a aliança não pode ser estipulada sem derramamento de sangue (Lc $22,19)$.

5. Jesus atribuiu um valor salvífico à sua morte que ele próprio previu? As afirmações de Jesus sobre sua tarefa (Lc 22,27), sobre o amor pelos inimigos e sobre sua dedicação aos pecadores, certamente preparam um discurso mais aprofundado sobre o valor de sua morte; valor salvífico que transparece com muita probabilidade do conceito de Litron, bem atestado pela tradição.

6. Jesus falou em público de sua morte iminente e de seu valor salvífico? É difícil que ele tenha falado em público do valor salvífico de sua morte. Certamente, o apresentar-se como "profeta não reconhecido" e as menções frequentes à morte dos profetas "mortos pelos seus pais" podiam sugerir um discurso semelhante.

7. Falou sobre isso com seus discípulos? Sabe-se que Jesus explicava muitas coisas aos seus discípulos. E tem fundamento a hipótese de que ele tenha falado explicitamente sobre isso. Mas é difícil descobrir os termos exatos que ele empregou, também porque os ouvidos dos discípulos eram particularmente refratários a esses assuntos. Com certeza entregou a eles o "mistério do reino"; mas logo com o conceito de "morte”? E com certeza insistiu sobre o valor de intercessão provocatória de sua morte (Mc 14,25), mas até que ponto ele foi explícito e até que ponto foi compreendido?

8. Na Última Ceia indicou o valor salvífico de sua morte? Para ele é muito importante o valor dos gestos e das palavras. Nos gestos, Jesus oferece a salvação escatológica com o dom do alimento e da bebida e garante que essa salvação está além da morte; com as palavras explica que sua morte iminente tem valor salvífico para 
os outros; a expressão que paira ao redor da partícula hypér é sem dúvida pré-pascal.

d) dentre os dados $\operatorname{certos}^{18}$ dos anúncios da paixão, o verbo paradídotai (certamente original) ilumina o sentido vivido por Jesus em relação à sua morte: a vontade do seu Pai a ser vivida na linha do Servo (Is 53).

e) portanto, essa interpretação, em seu conjunto, projeta luz sobre o caminho de Jesus em direção à sua paixão e morte, durante 0 período da "diáspora" (fora da Galileia): ele o viveu como profeta-servo perseguido (cr. João Batista) e como “justo-servo" perseguido ${ }^{19} \mathrm{em}$ prol da salvação dos homens. Esse papel - precedentemente apenas prefigurado nos símbolos e no culto - é prenunciado por Jesus e vivido por ele porque tem consciência da unicidade absoluta de sua existência humano-divina e de sua missão recebida em relação aos homens. É essa consciência de Jesus que constitui uma indicação cristológica indireta sobre o mistério de sua pessoa.

\section{D) Compreensão-reação dos discípulos}

Os Evangelhos Sinóticos registram com abundância de dados a reação dos discípulos diante da perspectiva de uma morte violenta e falimentar prenunciada por Jesus a respeito de si próprio. Não pretendemos examinar aqui detalhadamente os textos, nem mesmo resenhá-los todos.

Indicaremos as passagens mais evidentes: Mc 8,3; 2-33; 9,32; 10,$32 ; 14,26-29$ e paralelos. Qual o sentido geral dessas passagens? Vamos nos limitar a duas indicações gerais.

\footnotetext{
18 Cf. Jeremias, op. cit., p. 327.

19 Cf. o asham de Is 53,10.
} 
I. Os discípulos do grupo pré-pascal.

Nos Evangelhos aparece claramente que os discípulos não compreenderam o sentido da cruz de Jesus antes de sua ressurreição. E mais precisamente:

- as palavras de Jesus deixam claro para eles a referência à morte violenta por causa dos homens, a ponto de eles mostrarem resistência a essa perspectiva, tentando dissuadir Jesus de ir a Jerusalém;

- com referência ao sentido que Jesus atribui à sua morte, os discípulos não aceitam esse significado que se situa na linha do "servo" (Is 53): "Com efeito, pensam de acordo com os homens e não de acordo com Deus” (Mc 8,33).

\section{A nova compreensão à luz da páscoa}

Os Evangelhos revelam também os reflexos que a história pré-pascal de Jesus e dos discípulos teve nas primeiras décadas de vida eclesial. Podemos extrair alguns dados:

- os apóstolos e a Igreja apostólica procuraram o sentido profundo da morte de Jesus à luz do "Servo", sobretudo Is 53 e de outras figuras e profecias do Velho Testamento (cf. Fl 2, 6-11);

- também a aproximação ao mistério da consciência de Cristo - "aquele que morria para salvar todos os homens" - aparece desenvolvida pela Igreja apostólica: seja na redação dos dados pré-pascais, seja nas "teologias” dos outros escritos neotestamentários;

- na compreensão do valor da morte de Cristo é significativa a tentativa de Lucas de elaborar uma teologia e uma cristologia que não utilizem excessivamente a doutrina da satisfação vicária. Ele conceberia a morte do homem-Deus mais como um “morrer com” os homens do que um "morrer para pagar uma dívida feita pelos pecados dos homens"; o Cristo é mais o "chefe da vida" (archegós texéos: Atos, 3,15; 5,31), que, com seu “existir”, dá sentido também à morte do homem. 


\section{Conclusões}

Como para o tema dos banquetes de comunhão de Jesus com os homens, também para esses anúncios da própria morte por parte de Jesus é preciso esperar a última ceia com os discípulos e a instituição da Eucaristia para compreender o sentido cheio e perene atribuído pelo próprio Jesus.

No período do seu “exílio”, enquanto se dirigia para Jerusalém, Jesus anunciou o sentido profundo que - em conformidade com a vontade do Pai - ele estava dando à sua morte: somente ele, verdadeiro homem e verdadeiro Deus, poderia salvar todos os homens, realizando a profecia do "servo de Iahweh".

Evocando, após a Páscoa, aquele tempo e aquela escolha de Jesus, os discípulos poderão compreender que ele, daquela forma, tinha levantado o véu do mistério de sua consciência sobre si mesmo e sobre sua missão. Análoga "surpresa” eles tiveram quando de sua boca escutaram invocar Deus com o apelido Abbá; ou o ouviram tomar posição em relação à Toráh, não como os escribas, mas como alguém que tem autoridade (cf. Mt 7,29). Além disso, tinham consciência de que somente ele os podia ter chamado para se tornarem seus discípulos, com aquele "siga-me!" que nunca homem nenhum tinha pronunciado.

\section{A última ceia e o tema da aliança: "Em Jerusalém, Jesus denuncia a derrota da antiga aliança"}

Um terceiro período de ministério de Jesus, após aquele na Galileia e aquele "no exílio”, é suficientemente indicado pelos Evangelhos Sinóticos na última estadia de Jesus na cidade santa. Ele chega a Jerusalém e, após algum tempo de ministério junto ao templo, é preso e condenado à morte. Certamente Jesus tinha estado outras vezes na cidade santa em peregrinação por ocasião das grandes festas anuais: João deixa deduzir isso com sua referência a festas e celebrações no templo (cf. Jo, 2,12-23; 7-10). Entretanto os Sinóticos prestam atenção, 
sobretudo, a essa última permanência de Jesus em Jerusalém. Sua importância vem do fato de que Jesus toma uma posição profética em relação ao mundo religioso de seu povo. ${ }^{20}$

Os textos evangélicos (sinóticos) a que estamos nos referindo são os seguintes: Mt 21-25; Mc 11-13; Lc 19,28-21,38. Mesmo com estruturas e características redacionais diferentes, os Sinóticos atribuem a esse período alguns gestos e discursos bem precisos de Jesus sobre o culto do templo e a espiritualidade do antigo povo de Deus. Para o aprofundamento dessa seção, vejam-se os diversos comentários dos Evangelhos.

Pensamos que, nesta seção, podem ser indicados três temas sucessivos: condenação do culto do templo; Jesus recusa a interpretação da Torá feita pelos Escribas; predição do fim da antiga economia sinaítica.

\section{A) Condenação do culto do templo}

Os Evangelhos Sinóticos, unanimente, apresentam Jesus que toma posição diante de Jerusalém e do templo, no primeiro grupo dos textos referentes a Jesus que permanece na cidade santa pela última vez. Trata-se de: Mt 21,1-22; Mc 11,1-25; Lc 19,28-48.

Ao lado de uma primeira constatação sobre a "fonte" comum ou, também, sobre o esquema único de pregação presente na igreja apostólica, aparece evidente uma interpretação evangélica própria de cada redator. Pode-se conferir isso mediante uma sinopse:

1) atenção ao distinguir duas jornadas (cf. vv. 1 e 12) em Marcos, de acordo com o esquema litúrgico-catequético da última "semana" de Jesus, característica do segundo evangelho;

20 W. TRILLING, Le jugement sur le faux Israel, in L'annonce du Christ dans les Evangiles Synoptiques, Du Cerf, (Lectio divina 69), Paris 1971, pp, 165-189; X. LEON-DUFOUR, La parabola dei vignaioli omicidi, in Studi sul Vangelo, Ed. Paoline, Milano, pp. 419-478. 
2) omissão do gesto simbólico da figueira que foi amaldiçoada e secou em Lucas, que (em Lc 13,6-9) propõe a "parábola” da figueira com sentido contrário;

3) os destaques próprios de cada evangelista ao apresentar episódios comuns.

\section{Estrutura da seção}

Podemos, então, distinguir quatro temas diferentes nesse primeiro grupo de textos sobre Jesus em Jerusalém. ${ }^{21}$ E precisamente:

\section{a) Ingresso messiânico de Jesus}

Mt 21,1-11

Mc 11,1-11

Lc 19,28-40

Jo12,12-19

1) gesto profético de "purificação" do templo:

Mt 21,12-17

Mc 11,15-19

Lc 19,45-48

Jo 2,13-22

2) gesto profético-simbólico de maldição da figueira

Mt 21,18-22

Mc 11,12-14.20-22

3) choro de Jesus pela cidade santa: Lc 19,41-44.

O choro de Jesus por Jerusalém é característico de Lucas e de seu estilo, em comparação com o gesto da figueira amaldiçoada e do seu sentido em Mateus e Marcos. Poderia ser considerado - tanto o episódio da figueira maldita como aquele do choro de Jesus - o juízo de irrecuperabilidade da antiga aliança: quase a explicação do gesto profético da "purificação” do templo. É justamente sobre esse último ponto que efetuaremos alguns aprofundamentos.

21 H. SCHILIER, La fine del tempo, Paideia, Brescia, 1974, pp. 75-93; S. ZEDDA, L'escatologia bíblica, Vol I, Paideia, Brescia, 1972, pp. 331-398; J. DUPONT, Les trois apocalypses synoptiques. Marc 13; Mathieu 24-25; Luc 21, (Lectio divina, 121), du Cerf, Paris, 1985. 


\section{A "purificação" do templo}

a) A redação evangélica apresenta as notas teológico-pastorais próprias de cada evangelista, embora remeta para uma provável fonte comum pré-sinótica:

Mc 11,15-19: o juízo de Jesus sobre o templo. Há uma conexão evidente entre os dois gestos proféticos de Jesus que Marcos dispõe intencionalmente em forma de quiasmo:

- maldição da figueira: vv. 12-14

- purificação do templo: vv. 15-19

- reflexões sobre a figueira amaldiçoada: vv. 20, 15.

No nosso episódio: o gesto de Jesus não é uma purificação-reforma (a figueira amaldiçoada morre!), como tinha sido tentada e prenunciada no passado, mas uma condenação, ou seja, abolição de uma situação irrecuperável. A citação de Is 56,7 evoca a destinação universal do templo de Deus. O desafio contra o culto hebraico existia já em Mc 2, 23-3,6 (o Sábado) e tinha tido - aí (v. 6) como aqui (v. 18) - o efeito de projetar um complô contra Jesus (será esse também o ponto de acusação no processo religioso contra Jesus). Assim a ida de Jesus para o monte das Oliveiras e para Betânia supera o sentido descritivo imediato e expressa a saída de Deus do templo que não é mais a sua casa (cf. Ez 10,18-22; 11, 22-25). ${ }^{22}$

Mt 21,12-13: fim do culto israelita: Mateus segue Marcos, mas também o simplifica, pondo ordem nos seus temas. Estrutura:

- entrada messiânica (hosana...): vv. 1-1

- purificação do templo: vv. 12-13

- o novo povo ao redor de Jesus (hosana...): vv. 14-17.

A entrada messiânica está na mesma linha de Zc 9,9 (+ Is 62,11), mas dos três títulos "justo" (em outras passagens tão apreciado por Mt), "salvador" e "humilde" ( $a n i=$ ), Mateus toma somente esse último

22 Para aprofundamento, entre outros comentários sobre os evangelhos, veja: S. LEGASSE, Jésus et L'enfant, Gabalda, Paris 1969, pp. 246-268. 
(cf. Mt 5,5; 12,25-30). Jesus cavalga o burro não tanto da "pobreza" (era uma cavalgadura de rei: cf. 1R 1,33.38), mas da paz, em oposição ao cavalo da prepotência e da guerra (cf. Is 31,1-3; Mq 5, 9; Sal 20,8 ). Mateus alcança o ponto mais alto quando (somente ele, em comparação a Mc e Lc) reúne ao redor de Jesus o novo povo de "salvados" (aleijados, mancos) e de "pequenos" (que clamam pelo novo rei messiânico): ao fundo está o texto de Mt 12,25-30.

Lc 19,45-48: Jesus toma posse do templo. Lucas não traz o episódio simbólico da figueira amaldiçoada; em lugar disso há o choro de Jesus (vv. 41-44). A entrada profética de Jesus no templo é para tomar posse dele e ensinar, na linha de Mal 3,1-4.

Algumas anotações:

- omitindo os vv. 11 e 15 (de Mc 11), Lucas obtém o efeito de uma entrada messiânica diretamente no templo,

- sobriedade de Lucas ao evocar o gesto de expulsar os vendedores do templo;

- assim se realiza a profecia de Zc 14,11 (mais nenhum vendedor no templo);

- Jesus consagra o templo com sua presença e seus ensinamentos e o povo ouve Jesus (cf. Lc 2,49).

b) A pregação apostólica, que está refletida nos elementos comuns aos três textos sinóticos, indica no gesto de Jesus a atuação de esperas messiânicas e o contato com a experiência eclesial:

- esperas messiânicas: textos para leitura são: Jr 7,1-15 (fim do velho culto); Is 56, 3-7 (universalismo); Jr 8,13; Os 9,10-17; Mc 10,4 .

- atualidade: Jesus é o novo templo e o novo culto: Jo 2,13-22; At 7,47-54;

c) A experiência histórica de Jesus, indicada pelos textos evangélicos, parece ser especialmente aquela de um juízo duro e amargo contra o culto religioso de seu povo. Jesus sabe que está executando um gesto duro e amargo que o compromete irremediavelmente, mas 
faz isso porque aquele culto testemunha o fim da aliança mediante contrato.

B) A superação da interpretação da Torah feita pelos escribas e pelos fariseus.

Os Sinóticos apresentam - após o primeiro grupo de textos sobre o culto - um segundo grupo referente ao tema da Torah sinaítica, que degenerou em “leis” por causa da interpretação dos escribas. Já um conjunto de sentenças de Jesus tinha sido relacionado ao templo no período da “diáspora” de Jesus: Mc 7,1-23; Mt 15,1-12.

I. Estrutura da seção

Os três Sinóticos relatam um conjunto de diatribes entre Jesus e o mundo oficial hebraico: escribas, fariseus, saduceus.

Provavelmente há uma fonte comum pré-sinótica (cf. os vários comentários dos Evangelhos): sobre ela, cada evangelista "redigiu" seu próprio texto e mensagem. Eis o prospecto:

discussão sobre a autoridade de Jesus:

Mt 21,23-27 Mc 11,27-33;

Lc 20,10

parábola dos dois filhos:

Mt 21,28-32

parábola dos vinheiros:

Mt 21,33-46

Mc 12,1-12;

Lc 20,9-19

parábola das bodas reais:

Mt 22,1-14

o tributo a César:

Mt 22,15-22

Mc 12,13-17

Lc 20,20-26

a ressurreição dos mortos

Mt 22,23-33

Mc 12,18-27

Lc 20,27-40

o maior mandamento:

Mt 22,34-40

Mc 12,28-34

(Lc 10,25-37)

o Messias filho de David:

Mt 22,41-43

Mc 12,35-37

Lc 20,41-44

o juízo de Jesus sobre o mundo

Mt 23

Mc 12,38-44

Lc 20,45-21, 4. 
A primeira constatação sobre o prospecto precedente é um conjunto de dados textuais e temáticos:

- são comuns aos três Sinóticos e, portanto, pertencentes a uma provável fonte (escrita) comum, os textos n. 1. 3. 5. 6. (7). 8.9.;

- somente Mateus tem duas parábolas sobre a recusa de Israel: aquela dos dois filhos (cf. Lc 15,11-32); aquela dos convidados às bodas;

- a comparação central entre Jesus e o mundo dos escribas está na pergunta sobre o maior mandamento;

- o juízo de Jesus contra o mundo religioso dos escribas está resumido, sobretudo, na frase final “ai, de você” que Mateus desenvolve em todo o cap. 23.

\section{A parábola dos vinheiros homicidas}

É um gesto presente nos três Sinóticos e traz evidentes os sinais dos três momentos da sua história:

- as três "redações" evangélicas;

- sua elaboração na pregação apostólica;

- a mensagem original de Jesus.

No estado redacional presente, a parábola manifesta não somente o juízo de Jesus sobre a infidelidade de Israel, mas também uma profecia clara sobre o fim do mundo religioso nascido com a aliança sinaítica. ${ }^{23}$

C) Pregação do fim da antiga economia sinaítica

Uma página particularmente importante dos Evangelhos é o anúncio do fim do mundo.

23 W. TRILLING, Le jugement sur le fax Israel, in L'annonce du Christ dans les Evangiles Synoptiques, Du Cerf, (Lectio divina, 69), Paris 1971, pp, 165-189; X. LEON-DUFOUR, La parabola dei vignaioli omicidi, in Studi sul Vangelo. Ed. Paoline, Milano 1967, pp. 419-478. 
Sobre isso existem numerosos problemas interpretativos e as consequentes posições exegéticas e teológicas.

\section{As características dos três sinóticos}

É evidente o desenvolvimento redacional de cada evangelista nessa terceira parte dos textos e dos temas referentes à preparação da eucaristia, relacionados à permanência de Jesus em Jerusalém. Em seu desenvolvimento redacional, as três seções sinóticas podem ser caracterizadas e organizadas da seguinte forma:

a) Mr 13,1-37: O discurso escatológico de Jesus

1. 13,1-4: o cenário histórico: a majestade do templo;

2. 13,5b-6 e 21-23: alerta contra os impostores;

3. 13,7-8 e 14-2-: resposta à pergunta sobre o "sinal";

4. 13,9-13: os cristãos em situação de perseguição;

5. 13,24-27: a vinda do Filho do homem;

6. 13,28-31: certeza de que será logo;

7. 13,32-27: incerteza sobre o momento e convite a ficar de vigília As próprias palavras de Jesus (vv. 5-6, 9-13. 21-23. 28-37) inserem-se naquela que alguns críticos chamam "pequena apocalipse judaica" inspirada em Daniel (vv; 7-7. 14-20. 24-27).

b) Mt 24,1-25,36: O discurso sobre a parusia do Filho do homem

1. 24,1-3: ligação com o cap. 23;

2. 24,4-14: o começo do fim;

3. 24,15-28: o grande sofrimento final;

4. 24,20-31: a aparição do Filho do homem;

5. 24,32-35: iminência do fim;

6. 24,36-25, 25, 30: incerteza sobre o dia e a hora;

7. 25,31-46: o juízo do Filho do homem.

Ao discurso de Mc, que dizia respeito somente ao fim de Jerusalém, Mt acrescenta o tema do fim do mundo e completa a tradução precedente de maneira tríplice: 
- acréscimo dos vv. 26-28 e 37-41, retomados de um discurso sobre o dia do Filho do homem que Lc também utilizará (Lc 17,22-37);

- retoques que introduzem o tema da "parusia" (vv. 3.27. 37.39, nunca presente em outras passagens dos Evangelhos, cf. Mt 24,3 e par.; 1Cor 15,23 e par.) e do "sinal do Filho do homem" que impressionará todos os povos da terra (v. 30);

- acréscimo, no final do discurso, de algumas parábolas sobre a vigilância $(24,42-25,30)$ que preparam a volta de Jesus e o grande juízo escatológico (25,31-46).

c) Lc 21,5-36: A longa marcha da libertação

1. 21,5-7: ocasião e ligação com o material precedente;

2. 21,8-9: aviso inicial;

3. 21,10-11: as perturbações cósmicas do fim;

4. 21,12-19: os cristãos na perseguição;

5. 21,20-24: os dias do castigo de Jerusalém;

6. 21,25-28: o cenário do fim;

7. 21,29-33: certeza da esperança cristã;

8. 21,34-36: aviso final.

Lc, que na perícope 17,22-37 já tinha falado da volta gloriosa de Jesus no final dos tempos, aqui segue fundamentalmente Mc, associando-o a outra fonte. Como Mc, focaliza o discurso sobre o fim de Jerusalém.

\section{Estrutura geral da seção}

Além das peculiaridades redacionais, nos Sinóticos persiste um forte paralelismo também em relação a esse grupo de textos e temas. Limitamo-nos a formulá-lo:

1) anúncio da destruição do templo:

Mt 24,12

Mc 13,1-2

Lc 21,5-6

2) os últimos tempos: heresias e perseguições:

Mt 24,3-4

Mc 13,3-13

Lc 21,7-19 
3) o grande "sofrimento" final:

Mt 24,15-25

Mc 13,14-23

Lc 21,20-24

4) a vinda do Filho do homem:

Mt 24,26-31

Mc 13,24-27

Lc 21,25-28

5) a parábola da figueira: convite a ser vigilante:

Mt 24,44

Mc 13,28-37

Lc 21,29-36

6) a parábola do "mordomo":

Mt 24,5-51

7) a parábola das dez "virgens":

Mt 25,1-13

8) a parábola dos talentos:

Mt 25,14-30

9) a parábola do juízo final:

Mt 25,31-46

III. O fim de Jerusalém

Embora a predição seja do fim de Jerusalém seja do início da “diáspora” definitiva do povo antigo do Sinai esteja relacionada - já na pregação apostólica (como é evidente) e de maneira especial pela redação de Mateus - a temas mais gerais apocalíptico-escatológicos, fica claro que a palavra de Jesus sobre o fim da cidade santa ocupa um lugar central e seu sentido "eucarístico" se percebe cada vem mais como remoção de uma realidade que deve ser eliminada a fim de se compreender o sentido da novidade que Jesus está criando. ${ }^{24}$

24 H. SCHELIER, La fine del tempo, Paideia, Brescia 1974, pp. 75-93; S. ZEDDA, L'escatologia bíblica, Vol I, Paideia, Brescia 1972, pp. 331-398; J. DUPONT, Les trois apocalipses synoptiques. Marc 13; Matthieu 24-25; Luc 21, (Lectio divina, 121), du Cerf, Paris 1985. 


\section{Conclusões}

À luz do que foi levantado nessa parte, podemos afirmar que os Evangelhos Sinóticos permitem reconstruir alguns elementos da pré-história e das "preparações" da última ceia pascal celebrada por Jesus com seus discípulos:

a) certamente os Evangelhos indicam as releituras apostólicas pós-pascais dos gestos do Jesus histórico:

1. a multiplicação dos pães com a fórmula "eucarística”: Mt 14,19 = 15,36. Mc 6,41 = 8,6; Lc 9,16; João 6,11;

2. a “divisão dos pães” em Marcos (Mc. 6,30-8,26);

3. o discurso sobre o "pão da vida" em João (Jo 6, 1-70);

4. o desenvolvimento dos temas referentes ao Servo $=$ Cristo nos Sinóticos (cf. Mt 8, 16-17; 12,15-21 etc.);

b) mas o próprio Jesus (o Jesus "histórico") vivenciou essa preparação e espera: assim os Evangelhos nos permitem percebê-lo. Procuramos evidenciar três capítulos:

1. seus banquetes de comunhão e reconciliação com os homens (especialmente durante o período galiléico);

2. o sentido dado por Jesus à sua morte como fato redentor universal na linha do servo de Iahwé, sobretudo na época de seu afastamento da Galiléia;

3. a superação qualitativa da antiga aliança, em seus elementos fundamentais: a Torah (= ensinamento) decaída em "leis" prescritivas vindas de fora e "ensinamentos" com horizontes limitados; com seu culto formal e privatizado (= sem vida e sem abertura); com a cidade santa reduzida a lugar de ambições e disputas pessoais (como aparece no juízo de Jesus durante sua última permanência em Jerusalém).

São precisamente esses dados - sobretudo aqueles de nível pré-pascal (isto é, os “facta et verba Jesu") - que permitem a compreensão mais profunda da instituição da Eucaristia durante a última ceia de Jesus com seus apóstolos: 
- ela tinha sido precedida e preparada como comunhão, sacrifício, aliança;

- ela se prepara para ser assim - por vontade de Cristo - zikkaron da nova páscoa de libertação, mas também sacramento (sinal e instrumento) de novos encontros entre Cristo e os homens, para renovar com eles comunhões, sacrifícios de redenção, novas alianças com Deus alicerçadas na mediação de Cristo (o "fiel”, segundo $\mathrm{Hb} 3,1-6)$.

\section{Bibliografia}

AA.VV., La sapienza dela croce, Vol. I, Elle Di Ci, Torino 1976 (specialmente, gli articoli di: C. Duquoc, pp. 11-14; AP. Gordo, pp. 106-125).

A. HEISING, La moltiplicazione dei pani (Studi biblici, 12), Paideia, Brescia 1970.

A. DEEKS, The Structure of the Fourth Gospel, New Testamente Studies, 15 (1968-69), pp. 107-129.

A. FEUILET, Les thèmes bibliques majeurs du discours sur le pain de vie, Nouvelle Revue Théologique, 82 (1960) 804822; 918-939; 1040-1062.

A. GEORGE, Comment Jésus a-t-il perçu as propre mort, "Lumière et Vie”, 20 (1971) 34-49.

A. MARCHADOUR, L'eucaristia nella Bibbia (Bibbia-oggi. Strumenti per viver ela parola, 23), Gribaudi, Torino 1983.

A. P. GORDO, Gli annunci dela passione, in La sapienza dela croce. Vol. I, Elle Di Ci, Torino 1976, pp. 106-125.

A. WINKLHOFER, L'Eucharistia come celebrazione pasquale, Morcelliana, Brescia 1968.

B. CECCOLIN, Eucaristia, la preparazione neotestamentaria, Messaggero, Padova, 1992.

B. M. F. VAN JERSEL, Da Gesù ai Vangeli, Assisi, Cittadella, 1971, p. 265-289.

C. GIRAUDO, La strutura letteraria della preghiera eucarística. Saggio sulla genesi letteraria di una forma. Toda veterostestamentaria, beraka 
giudaica, anáfora Cristiana, (Analecta bíblica, 92), B.I. P. Press, Roma 1981.

E. GALBABIATI, L'Eucaristia nella Bibbia (cronache alla prova, Parole 1), Jaca Book, Milano 1983 (2).

F. LAMBIASI, L'autenticità storica dei Vangeli, Dehoniane, Bologna 1976.

F. MUSSER, Il Gesù storico e il Cristo della fede, in Esegesi e Dogmatica (a cura di H. Vorgrimler), Paoline, Roma 1967, pp. 263-321.

G. SEGALLA, Gesù pane del cielo. Eucaristia e cristologia in Giovanni (Conoscere il vangelo 6), Ed. Messagero, Padova 1976.

H. CAZALLES, Eucharistie, benediction et sacrifice dans l'Ancien Testament, La Maison-Dieux, 123 (1975), pp. 7-28.

H. CAZALLES, L'anaphore et l'Ancien Testament, in Eucharisties d'Orient e d'Occidente, vol. 1, Paris, 1970, pp 11-12.

H. SCHILIER, La fine del tempo, Paideia, Brescia 1974, pp. 75-93.

H. SCHÜRMANN, Comment Jésus a-t-il vécu sa mort? Exégèse et théologie (Lectio Divina, 93), Du Cerf, Paris, 1977.

H. SCHÜRMANN, Der historische Jesus und der Kerygmatische Christus (Herausgegeben von H. Ristow und K. Matthiae), Berlin 1962.

J. COPPENS, Eucharistie, in Dictionnaire de la Bible, Supplement, I (1928), col. 1146-1212.

J. COPPENS, L'Eucharistie néotestamentaire, in Exégese et Théologie, II, Gembloux-Parigi 1968, p. 262-281.

J. DUPONT, Les trois apocalypses synoptiques. Mar 13; Matthieu 24-25; Luc 21, (Lectio divina, 121), du Cerf, Paris 1985.

J. GIBLET, L'Eucaristia nel Vangelo di Giovanni: una lettera di Gv. 6: Concilium (1968/10) 70-79.

J. GUILLET, Gesù di fronte alla sua vita e alla sua morte, Cittadella, Assisi 1972.

J. JEREMIAS, Teologia del Nuovo Testamento, Paideia, Brescia 1976, pp. 351-326.

J. L. CHORDAT, Jésus devant as mort dans l'Evangile de Marc, Du Cerf, Paris 1972. 
J. M. CANGH, La multiplication des pains et l'Eucharistie (Lectio divina, 86), Du Cerf, Paris 1975.

J. M. VAN CANGH, La multiplication des pains et l'Eucharistie (Lectio divina, 86), Du Cerf, Paris 1975.

J. RADERMAKES, Il Vangelo di Gesù secondo Marco (Lettura pastorale della Bibbia), EDB, Bologna 1975. (Edição original em francês 1974).

L. BEAUDUIN, La Piété de l'Église, Parigi, 1914.

L. BOUYER, Eucharistie. Théologie et spiritualité de la prière eucharistique, Desclée, Tournai 1966.

L. CERFAUX, La section des pains, in Recueil L. Cerfaux, Duculot, Gembloux 1954, t. I, pp. 471-481.

L. J. LIEBREICH, The impacto of Nehemiah 9; 5-37. In the liturgy oh the Synagogue, 1974.

M. BASTIN, Jésus devant as mort (Lectio Divina, 92), Du Cerf, Paris 1976.

M. CONTI, Il discorso del pane di vita nella tardizione sapienziale, Levanto 1967.

M. GOUGUERS (a cura), Jésus devant sa passion et as mort ("Cahiers Evangile”, 30), Du Cerf, Paris 1979.

M. THURIAN, Eucharistie, memoriale de Signore, sacrifício di azione di grazia e d'intercessione (Teologia oggi, 5), Ed. A.V.E., Roma 1967.

N. FÜGLISTER, Il valore salvifico della pasqua, Brescia, Paideia 1977.

P. BEAUCHAMP, Le Récit, la Lettre, Le Corpus, Paris 1982; Création et foundation de la loi, Gn 1, 29s, in La Créarion dnas la Bible et l'Ancien Orient, Paris, Lectio divina 127, 1986.

P. DUMOULIN, Entre la Manne et l'Eucharistié. Étude de Sg .16,15-17, 1a Manne dans livre de la Sagesse sythèse de traditions et préparation au Mystère Eucharistique, (Analecta bíblica, 132), Ed. Pontificio Istituto bíblico, Roma 1994.

P. GARDIEL. La Cène et croix. Après René Girard: réflexion sur la mort rédemptrice, Nouvelle Revue Théologique, 101 (1979) 676-698.

R. BULTMANN, Theologie des Neuven Testaments, Tubingen, 9. edição, 1984. 
R. DE VAUX, Istituzioni dell'Antico Testamento, Marietti, Torino 1964, pp. 433-441.

R. LE DEAUT, La nuit paschale, P.I.B., Roma 1963.

R. MORGENTTHALER, Die lukanische Geshichtsshreibung als Zeugnis, I, Zurich 1049, p. 156.

S. LEGASSE, Jésus et l'enfant, Gabalda, Paris 1969, pp. 246-268.

S. ZADDA, L'escatologia bíblica, Vol I, Paideia, Brescia 1972, pp. 331-398.

T. DE MOPSUÈSTIA, Homilias catequéticas, 428.

W. C. ROBINSON, The Theological Content for Interpreting Luke's Travel Narrative, JBS 79 (1960) 20-31.

W. GRUNDMANN, Frangen der Komposition des lukanischen Reiseberichtes, Zeitschrift für neutestamentliche Wissenschaft, 50 (1959) 252-270.

W. TRILLING, Le jugement sur le faux Israel, in L'annonce du Christ dans les Evangiles Synoptiques, Du Cerf (Lectio divina, 69), Paris 1971, pp. 165-189.

X. LEON DUFOUR, Condividere il pane eucarístico secondo il Nuovo Testamento, Elle Di Ci, Torino 1983 (tradução do francês, Paris 1982).

X. LEON-DUFOUR, Face à la mort, Jésus et Paul ("Parole de Dieu”, 18), Du Seuil, Paris 1979.

X. LEON-DUFOUR, La parabola dei vignaioli omicidi, in Studi sul Vangelo, Ed. Paoline, Milano 1976, pp. 419-478.

Recebido em: 06/09/2017

Aprovado em: 20/10/2017 